\title{
Factors That Influence the Choice of Dialysis Modality in the Elderly
}

\author{
Ana Elizabeth Figueiredoํ, Angélica Ribeiro de Freitas², Jéssica da Silva Lopes², \\ Danusa Pires ${ }^{2}$ \\ ${ }^{1}$ School of Nursing, Nutrition and Physiotherapy, Pontifícia Universidade Católica do Rio Gramde do Sul, Porto \\ Alegre, Brazil \\ ${ }^{2}$ Pontifical Catholic University of Rio Grande do Sul, Porto Alegre, Brazil \\ Email: anaef@pucrs.br
}

Received 14 October 2014; revised 16 November 2014; accepted 29 November 2014

Academic Editor: Rie Chiba, Jichi Medical University, Japan

Copyright (C) 2014 by authors and Scientific Research Publishing Inc.

This work is licensed under the Creative Commons Attribution International License (CC BY). http://creativecommons.org/licenses/by/4.0/

c) (7) Open Access

\begin{abstract}
This study aimed to identify the influencing factors on choice of dialysis modality in patients aged 60 years or more and the barriers and/or facilitators in the decision-making process. A descriptive, cross-sectional study was conducted involving patients undergoing renal replacement therapy for at least three months. Of the 55 patients included, $35(64 \%)$ were under medical care before starting dialysis. The majority of patients, $55 \%$ (30), reported being consulted regarding the type of dialysis they would like. The most chosen therapy was hemodialysis with physician indication being the most influencing factor on the choice of dialysis modality. Visual and mobility problems were those principally reported by the elderly participants. This study suggests the need for greater pre-dialysis participation by the multidisciplinary team and emphasizes the importance of patient involvement in the decision-making process.
\end{abstract}

\section{Keywords}

Elderly, Chronic Renal Insufficiency, Renal Dialysis

\section{Introduction}

The World Health Organization (WHO) defines the elderly in developing countries as being the population over 60 years of age, with this figure increasing to 65 years for developed countries. This population has increased considerably since the beginning of the 1950s. The number of elderly people has increased by $700 \%$ in fifty years and is estimated to reach 32 million by 2020 [1] [2].

Anatomical and physiological changes in the kidneys arising from the renal aging process represent an aggravating factor for renal pathology in the elderly and increase susceptibility to renal dysfunction over the years. 
These changes, together with diseases such as arterial hypertension, diabetes mellitus and heart failure, further exacerbate renal disease [3].

Research conducted in England has shown that 25\% of the elderly over 70 years and $30 \%$ over 80 years have chronic kidney disease, as compared to $11 \%$ of the general population [4]. In France, about $40 \%$ of dialysis patients are older than 75 years, while according to the 2010 dialysis census of the Brazilian Society of Nephrology (SBN-Sociedade Brasileira de Nefrologia), 31.9\% of patients requiring dialysis are 65 years or more [5] [6].

In chronic kidney disease, the decline of renal function in the elderly is very slow with no difference in survival when dialysis is initiated with a glomerular filtration rate of $10-14 \mathrm{ml} / \mathrm{min}^{\prime} 1.73 \mathrm{~m}^{2}$ or $<5-7 \mathrm{ml} / \mathrm{min} / 1.73 \mathrm{~m}^{2}$. However, early onset does have an important impact on quality of life for those people affected [4].

Current methods of renal replacement therapy (RRT) for renal function are hemodialysis (HD) through an arteriovenous fistula, peritoneal dialysis (PD) by means of a catheter inserted in the peritoneum and kidney transplantation where a kidney from a donor (living or deceased) is implanted in the recipient. These treatments sustain life but are not a cure for chronic renal insufficiency (CRI) [3].

The need for dialysis should be planned in advance so as to enable appropriate training of the patient in the case of PD and the creation of vascular access in the case of HD. The survival rates for elderly patients starting dialysis are surprisingly good, at around $50 \%$ by the end of a three-year period [7].

There is no consensus on what constitutes the best form of treatment for the elderly between peritoneal dialysis and hemodialysis. Both options have advantages and disadvantages and the two methods involve adaptation to new requirements for both the elderly patient themselves and their family or caregivers. All will require knowledge regarding the therapy and how to perform self-monitoring and care [8] [9].

The big difference in method use in Brazil with 90\% of patients receiving HD and 10\% PD, the visible increase in numbers of patients with chronic kidney disease, and the fact that $90.6 \%$ of these in all age groups use $\mathrm{HD}$ as the renal replacement therapy, have all attracted the attention of the researchers and prompted curiosity as to the underlying reasons that lead individuals to decide on a dialysis choice or interfere in that decision. It is known that other factors, such as dementia or depression, can interfere with the decision-making process [3] [5].

The aim of this study is to determine which factors influence the choice of dialysis modality and which health problems/difficulties are associated with this choice, focusing on patients aged 60 years or more, which is the fastest growing age group on dialysis.

\section{Method Employed}

A descriptive, cross-sectional study was conducted involving 55 of the 69 elderly patients with chronic kidney disease on dialysis at the Hospital São Lucas, Pontifícia Universidade Católica do Rio Gramde do Sul (HSLPUCRS), with 52 patients receiving hemodialysis (HD) and 17 on peritoneal dialysis (PD). Inclusion criteria were being aged 60 years or above, having received dialysis therapy for at least three months and having agreed to take part in the research. Patients were selected on the basis of meeting these criteria.

A closed-ended questionnaire developed by the researchers was used as the data collection instrument in relation to the decision-making process for dialysis method.

The Mini-Mental State Examination (MMSE) was chosen to screen for cognitive impairment of the patients involved in the study. Those patients scoring above 27 points were considered to have normal cognition, with the maximum possible score being 30 . Those scoring less than or equal to 24 points were considered to have dementia. The points were adjusted to take account of educational level with a cut-off score of 17 for those with less than 4 years of schooling. For patients with visual impairment the cut-off score was 22, with the maximum score being 25 [10].

The collected data was analyzed using descriptive statistics, with continuous variables being expressed as mean and standard deviation for those with normal distribution. Categorical variables were expressed as frequency and percentage.

Data collection took place at the dialysis unit of the HSL-PUCRS after approval of the project by the Scientific Committee of the School of Nursing, Nutrition, and Physiotherapy (FAENFI—Faculdade de Enfermagem, Nutrição e Fisioterapia) and the Research Ethics Committee of PUCRS, under no. 62188.

\section{Results}

A total of 55 patients receiving dialysis for more than three months and aged 60 years or more were included in the study; 41 of these on HD and 14 on PD. The patient clinical and demographic data are presented in Table 1. 
Table 1. Clinical and demographic data of the sample patients, Porto Alegre, 2012/2013.

\begin{tabular}{cccc}
\hline Variables & & & \% \\
\hline Gender & Male & 35 & 67 \\
Age (years) & Illiterate & $69.7 \pm 7.4$ & 15 \\
& Less than 4 years & 8 & 17 \\
Education & 4 to 8 years & 9 & 22 \\
& 8 to 11 years & 13 & 18 \\
& More than 11 years & 10 & 28 \\
& Spouse/partner & 15 & 56 \\
& Other family & 31 & 17 \\
With whom the patient lives & Alone & 10 & 10 \\
& Spouse/partner and other family & 7 & 2 \\
Mean time on dialysis & Institutionalized & 5 & 2
\end{tabular}

"SAH = systemic arterial hypertension.

Of the patients forming the sample, $80 \%$ (44) had never experienced another form of dialysis, whereas $20 \%$ (11) had already done so; of these, 45\% (5) had experienced PD and 45\% (5) HD. The change in dialysis method was determined in $45 \%$ (5) of cases by other comorbidities, peritonitis in PD, and in $45 \%$ (5) of cases through a lack of access to HD. One patient (10\%) changed due to receiving a kidney transplant.

The questionnaire revealed that $64 \%$ (35) of participants were under medical supervision prior to the beginning of dialysis and 36\% (20) had not undergone previous monitoring. When asked about their knowledge of another form of dialysis, 77\% (47) said they were aware and 23\% (8) said they had no knowledge regarding this.

Information about the different forms of dialysis was provided in 51\% (27) of cases by the physician, $15 \%$ (8) received this information from a nurse, $24 \%$ (13) from the physician and nurse and $4 \%$ (2) from other professionals.

The problems/difficulties most reported by the elderly participants were: visual complications in $51 \%$ (28) of cases, followed by $42 \%$ (23) with mobility problems and 31\% (17) expressing difficulty in writing.

The MMSE was used to evaluate the cognitive state of patients with the mean exam score being $24.27 \pm 4.1$ points. Seven of the 55 participants presented scores below the research cut-off point and were included since these were not related to their mental state, but to their physical difficulties at the time of the interview.

The majority of patients, 55\% (30), reported being consulted about the type of dialysis they would like to follow, whilst $45 \%$ (25) indicated they had not been questioned on the matter. It was observed that in 53\% (29) of cases the decision regarding the chosen dialysis method was made by the medical team and in $34 \%$ (19) of cases the decision was made by the patient.

The factors influencing the decision regarding the method of dialysis used were: $40 \%$ (20) medical team, $7 \%$ (4) left the decision to the team and did not wish to be involved, $6 \%$ reported difficulty in learning the process for PD therapy, $6 \%$ (3) did not want therapy at home, $4 \%$ the length of time required for PD, $10 \%$ (5) considered the convenience for the family, 3\% (1) indicated a fear of the hemodialysis machine, 3\% (1) had sudden onset and did not subsequently want to alter treatment, 3\% (1) had an inability to undergo PD due to cancer, 3\% (1) 
did not want PD, and 22\% (12) of patients could not say.

A total of $64 \%$ (35) of patients were under medical supervision before the beginning of dialysis therapy and of these, $9 \%$ (8) were illiterate, 43\% (22) had an elementary level education, 19\% (10) a high school level and $29 \%$ (15) a higher education level.

\section{Discussion}

The data obtained from this research in relation to the gender distribution of sample patients revealed a predominance of men among the chronic kidney disease patients over 60 years of age on dialysis. This is consistent with findings from other studies and with the 2010 dialysis census of the SBN [11]-[13].

The SBN 2010 dialysis census and other research have also demonstrated a predominance of systemic arterial hypertension (SAH), followed by diabetes mellitus (DM), as the underlying diseases that evolve to chronic renal insuficiency [11]-[13].

The pathologies encountered in the research of the elderly did not differ from those found in other senior populations not requiring renal replacement therapy (RRT). The most prevalent diseases found in two researches were SAH with a prevalence of $50 \%$ in a general elderly population, and DM with a prevalence of $17.3 \%$ in a population with an age range of 60 to 69 years [14] [15]. The study conducted at HSL-PUCRS demonstrated a prevalence of SAH and DM of $71 \%$ and $45.5 \%$, respectively, from the total number of patients interviewed.

Unlike as happens in most dialysis centers in Brazil where late referral to the nephrologist occurs, BASTO et al. [16] demonstrated a study where most patients were accompanied before starting dialysis, irrespective of level of education. Illiterate patients accounted for the smallest percentage of the research sample with 53\% having up to eight years education and $47 \%$ having eight years or more. It was not possible from this to make a direct correlation for years of schooling with CRI in the elderly patients and their choice of dialysis method. This study did not show the relationship between medical care before starting dialysis therapy and patient educational level. Regardless of this, however, it did demonstrate that in more than $50 \%$ of cases the patient was under medical care before beginning dialysis.

A French study observed that despite previous monitoring, 32\% of patients that began RRT did so with HD in an unplanned manner [17].

HD was the most favored therapy and medical recommendation was primarily the most influential factor for choice of dialysis modality in the elderly with chronic kidney disease. Since the majority of the sample interviewed left the decision regarding choice of dialysis modality to the medical team, there would appear to be a bias among physicians and nurses that creates a barrier for the indication of peritoneal dialysis for the elderly [18].

This coincides with data from Brown, where PD in the elderly over 70 years of age was shown on a smaller scale and may be directly related to who makes the choice of dialysis method [5].

Patients migrated from one dialysis therapy to another due to a lack of access or associated comorbidities. No other reason for motivation of the patient to change dialysis therapy was presented to the researchers.

Visual and mobility problems were the principal issues mentioned by patients, thereby identifying the problems that can most interfere in the quality of self-care for the elderly with chronic kidney disease. This is consistent with the reported data, principally as the underlying disease, DM, can cause retinopathy [19]. Oliver et al. in research with patients eligible for PD observed that one of the biggest barriers was a lack of strength and visual problems [20].

A study conducted in seven countries of Latin America and the Caribbean Islands involving individuals aged 75 years or more ranked Brazil third with a $28.6 \%$ prevalence of functional incapacity related to basic activities, and first with a 33.8\% prevalence of disability for instrumental activities, which includes the learning process of dialysis therapies [21].

Research carried out in London observed that visual impairment and compromised physical and cognitive function, depression and social isolation are factors reported as barriers to choice of dialysis method or adherence to peritoneal dialysis, in agreement with the data obtained in the present study [18].

The prevalence of cognitive impairment in chronic kidney disease patients ranged from $16 \%$ to $38 \%$ depending on the tests employed, although $0 \%$ was found among the elderly in the present study [22].

The mean time on dialysis in this study was 37.2 months, ranging from 3 to 204 months, with half the patients receiving dialysis for more than 24 months. Another research conducted presented data referring to 27 months of 
hemodialysis treatment, with data varying from 6 to 117 months [22].

A limitation of this study is that the knowledge of the interviewed patients related to peritoneal dialysis was not assessed.

Cognitive deficits that could have affected the choice of dialysis method were not detected and the main selfperceived problems/barriers of those interviewed were the difficulties in vision and writing, which may be related to each other and also with difficulty in learning the method of performing peritoneal dialysis.

\section{Conclusions}

HD was the most favored therapy and the most influential factor for choice of dialysis modality in the elderly with chronic kidney disease was primarily medical recommendation.

This research suggests the need for the multidisciplinary team to demonstrate to patients the importance of their participation in the decision-making process, and not to be simply spectators of their care. They should also actively participate in the health-disease process, solving doubts, questioning and engaging in the choices proposed by a team that must have impartiality as its principal characteristic.

\section{Acknowledgements}

A .R. F. has a research scholarship from Pontifical Catholic University of Rio Grande do Sul.

\section{References}

[1] Costa, M.F.L. and Veras, R. (2003) Saúde pública e envelhecimento. Cadernos de Saúde Pública, 19, 700-701. http://dx.doi.org/10.1590/S0102-311X2003000300001

[2] Veras, R. (2009) Envelhecimento populacional contemporâneo: Demandas, desafios e inovações. Revista de Saúde Pública, 43, 548-554. http://dx.doi.org/10.1590/S0034-89102009000300020

[3] Kusumota, L., Rodrigues, R.A.P. and Marques, S. (2004) Idosos com insuficiência renal crônica: Alterações do estado de saúde. Revista Latino-Americana de Enfermagem, 12, 525-532. http://dx.doi.org/10.1590/S0104-11692004000300011

[4] Brown, E.A. and Johansson, L. (2011) Epidemiology and Management of End-Stage Renal Disease in the Elderly. Nature Reviews Nephrology, 7, 591-598. http://dx.doi.org/10.1038/nrneph.2011.113

[5] Brown, E.A. (2008) Should Older Patients Be Offered Peritoneal Dialysis? Peritoneal Dialysis International, 28, 444448.

[6] Sesso, R.C., Lopes, A.A., Thomé, F.S., Lugon, J.R. and Santos, D.R. (2011) Relatório do censo brasileiro de diálise de 2010. Jornal Brasileiro de Nefrologia, 33, 442-447. http://dx.doi.org/10.1590/S0101-28002011000400009

[7] Howley, E. and Zawada, E. (2012) Indicações para Diálise, Capítulo 01. 2010. http://www.bibliomed.com.br/bibliomed/bmbooks/nefrolog/livro1/cap/cap01.htm

[8] Kusumoto, L., Marques, S., Haas, V.J. and Rodrigues, R.A.P. (2008) Adultos e idosos em hemodiálise: Avaliação da qualidade de vida relacionada à saúde. Acta Paulista de Enfermagem, 21, 152-159. http://dx.doi.org/10.1590/S0103-21002008000500003

[9] Franco, M.R.G. and Fernandes, N.M.S. (2013) Diálise no paciente idoso: Um desafio do século XXI—Revisão narrativa. Jornal Brasileiro de Nefrologia, 35, 132-141. http://dx.doi.org/10.5935/0101-2800.20130022

[10] Bertolucci, P.H.F. (1994) Mini-exame do estado mental em uma população geral. Arquivos de Neuro-Psiquiatria, 52, 1-7. http://dx.doi.org/10.1590/S0004-282X1994000100001

[11] Cassini, A., Malagutti, W., Rodrigues, F., Deus, R., Barnabé, A., Francisco, L. and Ferraz, R. (2010) Avaliação dos Principais Fatores Etiológicos em Indivíduos Portadores de Insuficiência Renal Crônica em Hemodiálise. Conscientiae Saúde, 9, 462-468.

[12] (2010) Censo de Diálise SBN 2011. http://www.sbn.org.br/pdf/censo_2011_publico.pdf

[13] Reali, T. (2007) Perfil Socioeconômico dos Pacientes com Insuficiência Renal Crônica em Hemodiálise na região noroeste do Rio Grande do Sul/Brasil. Dissertação, Universidade Federal Do Rio Grande Do Sul, Porto Alegre. http://www.lume.ufrgs.br/bitstream/handle/10183/8839/000589745.pdf?sequence=1

[14] Oliveira, T., Araujo, T., Melo, E. and Almeida, D. (2002) Avaliação do Processo Adaptativo de um Idoso Portador de Hipertensão Arterial. Revista Latino-Americana de Enfermagem, 10, 530-536. http://dx.doi.org/10.1590/S0104-11692002000400010

[15] Tavares, D., Rodrigues, F., Silva, C. and Miranzi, S. (2007) Caracterização de Idosos Diabéticos Atendidos na Atenção 
Secundária. Ciência \& Saúde Coletiva, 12, 1341-1352.

[16] Bastos, M.G., Carmo, W.B., Abrita, R.R., Almeida, E.C., Mafra, D., Costa, D.M.N., Gonçalves, J.A., Oliveira, L.A., Santos, F.R. and Paula, R.B. (2004) Doença Renal Crônica: Problemas e Soluções. Jornal Brasileiro de Nefrologia, 26, 202-215.

[17] Couchoud, C., Moranne, O., Frimat, L., Labeeuw, M., Allot, V. and Stengel, B. (2007) Associations between Comorbidities, Treatment Choice and Outcome in the Elderly with End-Stage Renal Disease. Nephrology Dialysis Transplantation, 22, 3246-3254. http://dx.doi.org/10.1093/ndt/gfm400

[18] Brown, E.A. (2011) How to Address Barriers to Peritoneal Dialysis in the Elderly. Peritoneal Dialysis Internayional, 31, 83-85. http://dx.doi.org/10.3747/pdi.2009.00160

[19] Eli, F. (2012) Os Olhos [base de dados na Internet]. Capítulo 37. https://www.bibliomed.com.br/bibliomed/bmbooks/nefrolog/livro1/cap/cap37.htm

[20] Oliver, M.J., Quinn, R.R., Richardson, E.P., Kiss, A.J., Lamping, D.L. and Manns, B.J. (2007) Home Care Assistance and the Utilization of Peritoneal Dialysis. Kidney International, 71, 673-678. http://dx.doi.org/10.1038/sj.ki.5002107

[21] Del Duca, G.F., Silva, M. and Hallal, P. (2009) Disability in Relation to Basic and Instrumental Activities of Daily Living among Elderly Subjects. Revista de Saúde Pública, 43, 796-805. http://dx.doi.org/10.1590/S0034-89102009005000057

[22] Tamura, M.K. and Yaffe, K. (2011) Dementia and Cognitive Impairment in ESRD: Diagnostic and Therapeutic Strategies. Kidney International, 79, 14-22. http://dx.doi.org/10.1038/ki.2010.336 
Scientific Research Publishing (SCIRP) is one of the largest Open Access journal publishers. It is currently publishing more than 200 open access, online, peer-reviewed journals covering a wide range of academic disciplines. SCIRP serves the worldwide academic communities and contributes to the progress and application of science with its publication.

Other selected journals from SCIRP are listed as below. Submit your manuscript to us via either submit@scirp.org or Online Submission Portal.
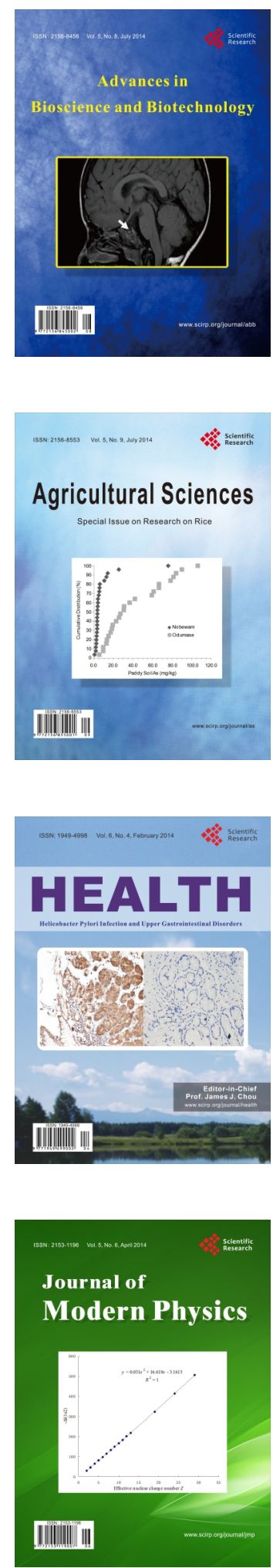
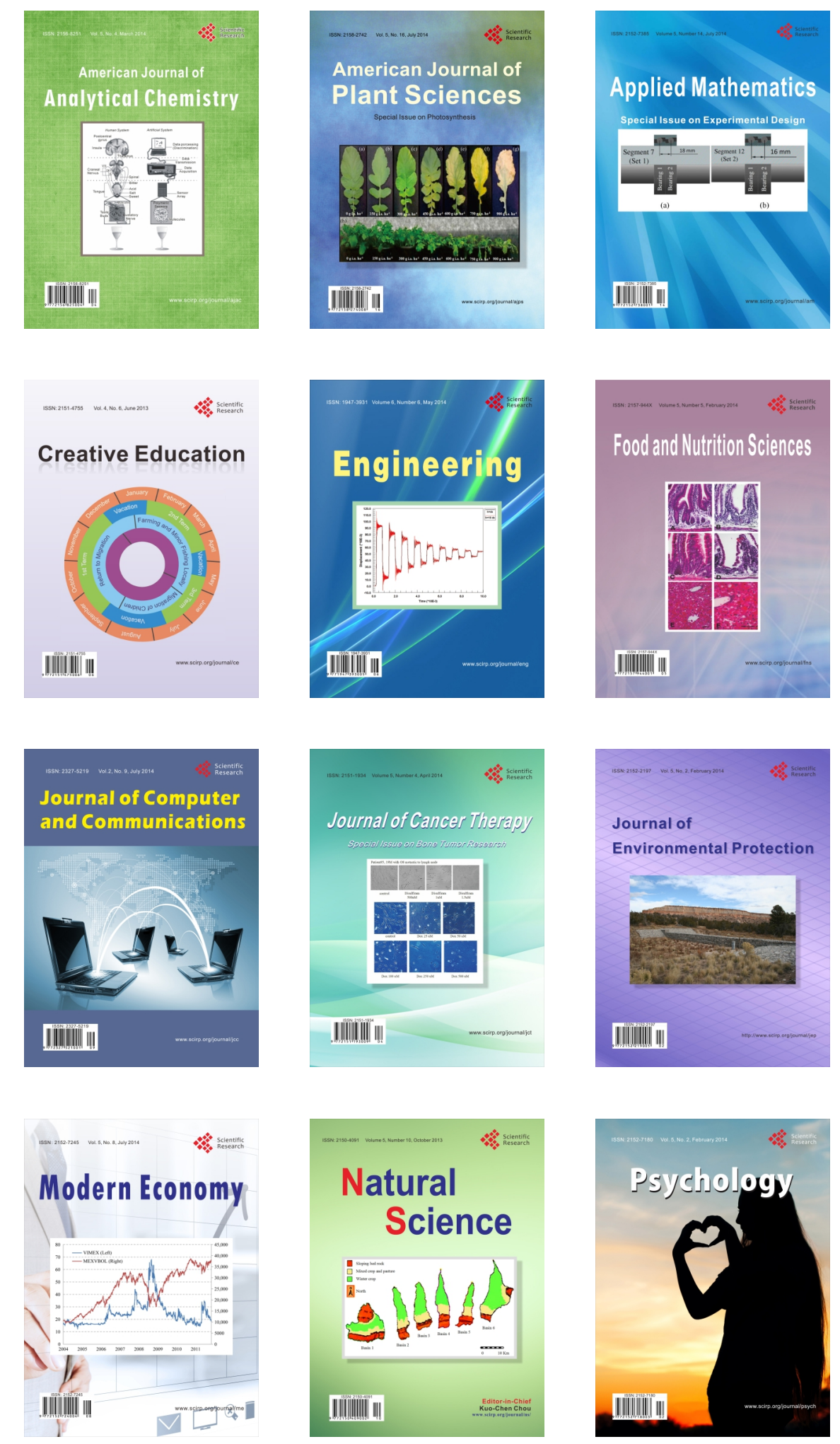